\title{
Sequential association of myogenic regulatory factors and E proteins at muscle-specific genes
}

\author{
Priya Londhe and Judith K Davie*
}

\begin{abstract}
Background: Gene expression in skeletal muscle is controlled by a family of basic helix-loop-helix transcription factors known as the myogenic regulatory factors (MRFs). The MRFs work in conjunction with $\mathrm{E}$ proteins to regulate gene expression during myogenesis. However, the precise mechanism by which the MRFs activate gene expression is unclear. In this work, we sought to define the binding profiles of MRFs and E proteins on musclespecific genes throughout a time course of differentiation.

Results: We performed chromatin immunoprecipitation (ChIP) assays for myogenin, MyoD, Myf5 and E proteins over a time course of $C_{2} C_{12}$ differentiation, resulting in several surprising findings. The pattern of recruitment is specific to each promoter tested. The recruitment of $\mathrm{E}$ proteins often coincides with the arrival of the MRFs, but the binding profile does not entirely overlap with the MRF binding profiles. We found that E12/E47 is bound to certain promoters during proliferation, but every gene tested is preferentially bound by HEB during differentiation. We also show that MyoD, myogenin and Myf5 have transient roles on each of these promoters during muscle differentiation. We also found that RNA polymerase II occupancy correlates with the transcription profile of these promoters. ChIP sequencing assays confirmed that MyoD, myogenin and Myf5 co-occupy promoters.

Conclusions: Our data reveal the sequential association of MyoD, myogenin, Myf5 and HEB on muscle-specific promoters. These data suggest that each of the MRFs, including Myf5, contribute to gene expression at each of the geness analyzed here.. The dynamic binding profiles observed suggest that MRFs and E proteins are recruited independently to promoters.
\end{abstract}

\section{Background}

The entire process of skeletal muscle differentiation is controlled by four highly related basic helix-loop-helix (bHLH) proteins referred to as the myogenic regulatory factors (MRFs). The MRFs have distinct but overlapping patterns of gene expression during muscle development [1]. Gene knockouts of each factor in the mouse have revealed that each MRF has a unique role in skeletal muscle differentiation. Myf5, Myf6 (also known as MRF4) and MyoD are not required for viability, although each mutant has a distinct phenotype [2]. In the combined absence of Myf5, Myf6 and MyoD, myoblasts are not specified and no skeletal muscle forms, resulting in a lethal phenotype [3]. Myogenin is the only MRF singly required for viability $[4,5]$. Mice heterozygous for the null allele appear normal, while mice lacking myogenin die at

\footnotetext{
* Correspondence: jdavie@siumed.edu

Department of Biochemistry and Molecular Biology, Southern Illinois University School of Medicine, 1245 Lincoln Drive, Carbondale, IL 62901, USA
}

birth. The myogenin-null mice have myoblasts, but very few muscle fibers. This suggests that myogenin is not required for the specification of skeletal muscle, but is required for the later stages of myofiber fusion.

MyoD and myogenin have been shown to bind highly overlapping gene sets, although certain genes appear to be selective for either factor [6,7]. However, the high degree of overlap in the binding patterns suggests that the majority of genes utilize both factors to activate gene expression. Previous work has shown that certain genes require the sequential expression of both MyoD and myogenin to activate gene expression [7]. The present work suggests that the activation of specific targets requires $\mathrm{MyoD}$ and its associated chromatin-modifying activities before myogenin can activate transcription. Why MyoD cannot activate transcription without myogenin on these genes is still unknown.

Recent work on Myf5 has revealed unexpected roles for this factor in adult animals. As mentioned above,

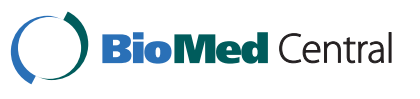


$M y f 5$ functions as a determination gene in early myogenesis. The role of Myf5 in later stages is unclear. In the absence of MyoD, Myf6 or myogenin, Myf5 is unable to promote differentiation from myoblasts [8]. This finding suggests that Myf5 functions only in muscle progenitor cells (MPCs) and myoblasts. However, recent work has shown that $M y f 5$-null mice exhibit impaired muscle regeneration with a significant increase in muscle fiber hypertrophy and a delay in differentiation [9]. However, satellite cell numbers were not significantly altered in the $M y f 5$-null animals, although a modest impaired proliferation was observed under some conditions in vitro. This work highlights the questions still remaining about the roles of the MRFs at distinct stages in myogenesis.

All bHLH transcription factors function as either homodimers or heterodimers. The bHLH transcription factors are loosely grouped into several categories: the widely expressed $\mathrm{E}$ proteins, including the $E 2 A$ gene products E12 and E47, HEB, E2-2 and Daughterless, are in the class I category and the MRF family is included in the tissue-specific class II category. Class II bHLH proteins form weak homodimers and preferentially heterodimerize with E proteins [10]. Prior in vitro experiments have demonstrated that the class II MRFs form avid heterodimers with class I E proteins, but homodimerize poorly in the presence of DNA sites [11-14]. Thus, it is thought that the MRFs function as heterodimers with ubiquitous E proteins. The E proteins suggested to be involved in skeletal muscle differentiation are the $E 2 A$ gene products E12 and E47, as well as HEB. Recent work has suggested that HEB may be the primary E protein that regulates skeletal muscle differentiation [15].

The MRFs all bind the canonical E-box consensus sequence, CANNTG. Genome-wide binding studies have revealed that both MyoD and myogenin preferentially bind E boxes with a consensus sequence of CASCTG (International Union of Pure and Applied Chemistry nomenclature http://www.iupac.org), where $S$ represents $\mathrm{G}$ or $\mathrm{C}[7,16]$. The site recognized at the highest frequency is CAGCTG. The sequences flanking the $\mathrm{E}$ box also make important contributions to the binding affinity and contribute to the overall consensus sequence elements determined for MyoD and myogenin $[11,16]$.

Given the high degree of overlap detected in the genome occupancy of MyoD and myogenin, we were interested in understanding the binding profile of these factors over a time course of differentiation. We were also interested in the binding profile of Myf5, as binding data for this factor during differentiation have not been reported. We also sought to compare the DNA-bound profiles of the MRFs with the E proteins. Thus, we initiated a temporal analysis of the binding of MyoD, Myf5, myogenin and the $E$ proteins in $C_{2} C_{12}$ cells, a widely used cell culture model for myoblast differentiation. These binding profiles were correlated with the levels of mRNA present in the cells, the levels of RNA polymerase II (RNAP II) occupancy and histone H3 acetylation present at the promoters. We show several novel findings. Surprisingly, we have found that the pattern of recruitment is unique to each gene, although some common features arise. As others have observed, we saw an early association of MyoD with most of these genes. In a cooperative pattern, myogenin then binds many of these promoters following MyoD. Unexpectedly, we found that Myf5 is also associated with genes expressed late in differentiation and often colocalizes with myogenin. We show that this colocalization also occurs in vivo at a late embryonic time point. The binding of each of the MRFs is transient. We also show that the occupancy of the E proteins is transient and that the occupancy often peaks concurrently with the peak in gene transcription. While the $E 2 A$ gene products could be detected on a few genes in our study in proliferating cells, HEB does appear to be the dominant $\mathrm{E}$ protein used during differentiation. At the genes occupied by E12/E47 in early myogenesis, we detected a switch in occupancy for HEB during differentiation. Taken together, our data suggest new models for the recruitment of MRFs and E proteins and support a novel role for Myf5 during differentiation.

\section{Results}

\section{Time course of MRF and E protein expression}

To initiate this work, we first characterized the available antibodies for these studies and confirmed MRF and E protein expression patterns over a time course of differentiation. We tested well-characterized antibodies for MyoD and myogenin [17,18]. We found that antibodies against MyoD and myogenin immunoprecipitated the target protein (data not shown) and did not recognize any of the other MRFs (Additional file 1 Figure S1). For Myf5, we tested commercially available antibodies for their ability to recognize and immunoprecipitate Myf5 specifically. We identified one antibody that immunoprecipitated Myf5 exclusively (Additional file 1 Figure S2), and this antibody was used for all the studies presented. We did note that the antibody does recognize recombinant MyoD by using Western blot analysis, but we could not immunoprecipitate this protein (Additional file 1 Figure $\mathrm{S} 2$ ). For the $\mathrm{E}$ proteins, we used antibodies raised against $\mathrm{HEB}$ and the $E 2 A$ gene products $\mathrm{E} 12$ and $\mathrm{E} 47$. The HEB antibody recognized E12/E47 on the basis of Western blot analysis, but immunoprecipitated HEB specifically (Additional file 1 Figure S3). The antibody against E12/E47 did not recognize or immunoprecipitate recombinant HEB (Additional file 1 Figure S4). Next, we examined the expression profile of the MRFs and HEB 
over an extended time course of $\mathrm{C}_{2} \mathrm{C}_{12}$ differentiation (Figure 1). As previously observed, MyoD and Myf5 were expressed in proliferating myoblasts. MyoD levels increased upon differentiation, but then rapidly decreased after two days of differentiation. Unexpectedly, Myf5 was expressed throughout the entire time course. Myogenin was not detectable in proliferating cells, but was rapidly upregulated upon differentiation. HEB was also expressed in proliferating myoblasts, but was steadily downregulated after about four days of differentiation. The E12/ E47 proteins were also expressed in proliferating myoblasts, but the expression decreased after two days of differentiation.

\section{Expression of genes chosen for analysis}

Several genes were chosen for this analysis. We chose muscle creatine kinase (Ckm) and desmin (Des), as both are well-characterized genes whose expression increases during differentiation. As the regulatory regions of these genes have been studied extensively by others, promoter proximal binding sites for the MRFs are well defined
[19-25]. We also chose the fast-twitch skeletal muscle troponin I, type 2 (Tnni2) and leiomodin $2(\operatorname{Lmod} 2)$ genes, as these have been characterized as myogenindependent targets in embryonic skeletal muscle during embryogenesis, and the promoter proximal MRF binding sites are known [26]. We also chose titin cap (Tcap), also known as telethonin. We have recently characterized the promoter proximal regulatory elements of the gene encoding Tcap and identified a promoter proximal fragment that recapitulates the expression pattern of Tcap in reporter assays and is bound by myogenin in vivo [27]. For each of these genes, we profiled the change in RNA expression profiles over a time course of differentiation.

For each gene, we saw that expression increased when cells began to differentiate, as expected (Figure 2A). Unexpectedly, we also observed that the expression continued to increase over several days of differentiationand reached very high levels of expression after six days of differentiation. We also observed that the expression levels significantly decreased for each gene, with the

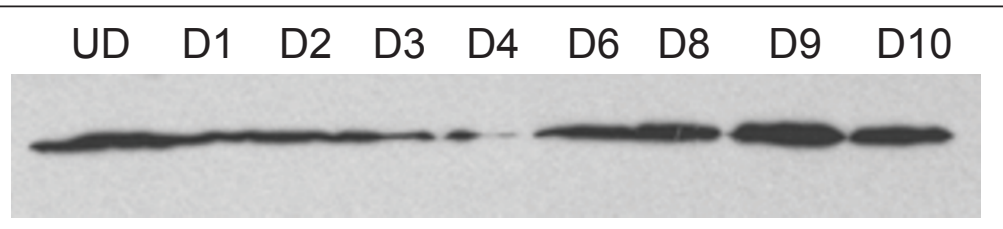

$\alpha-M y f 5$

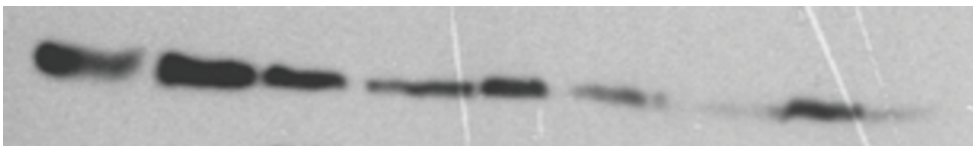

a-MyoD

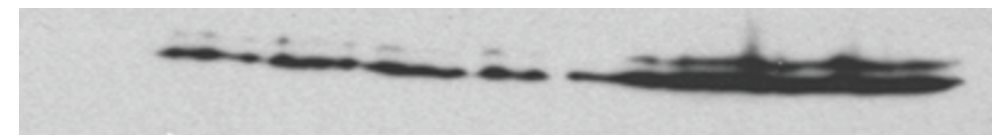

$\alpha$-myogenin

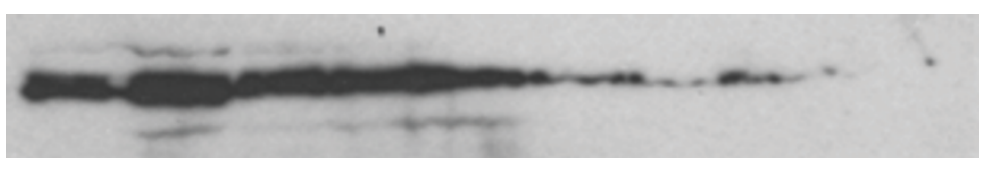

$\alpha-H E B$

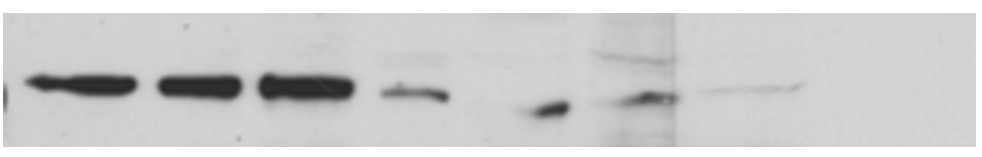

$\alpha-E 12 / 47$

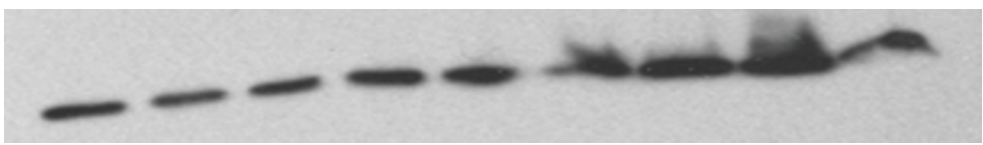

$\alpha-G A P D H$

Figure 1 Expression of myogenic regulatory factors (MRFs) and E proteins over a time course of differentiation in $C_{2} C_{12}$ cells. $C_{2} C_{12}$ cells were differentiated for the indicated number of days and harvested for protein (UD, undifferentiated cells; D1-D10, cells differentiated for the indicated number of days). Protein concentration was determined for each extract and used to normalize the sample loading. Parallel blots were probed for each of the indicated antibodies as described in Methods. 


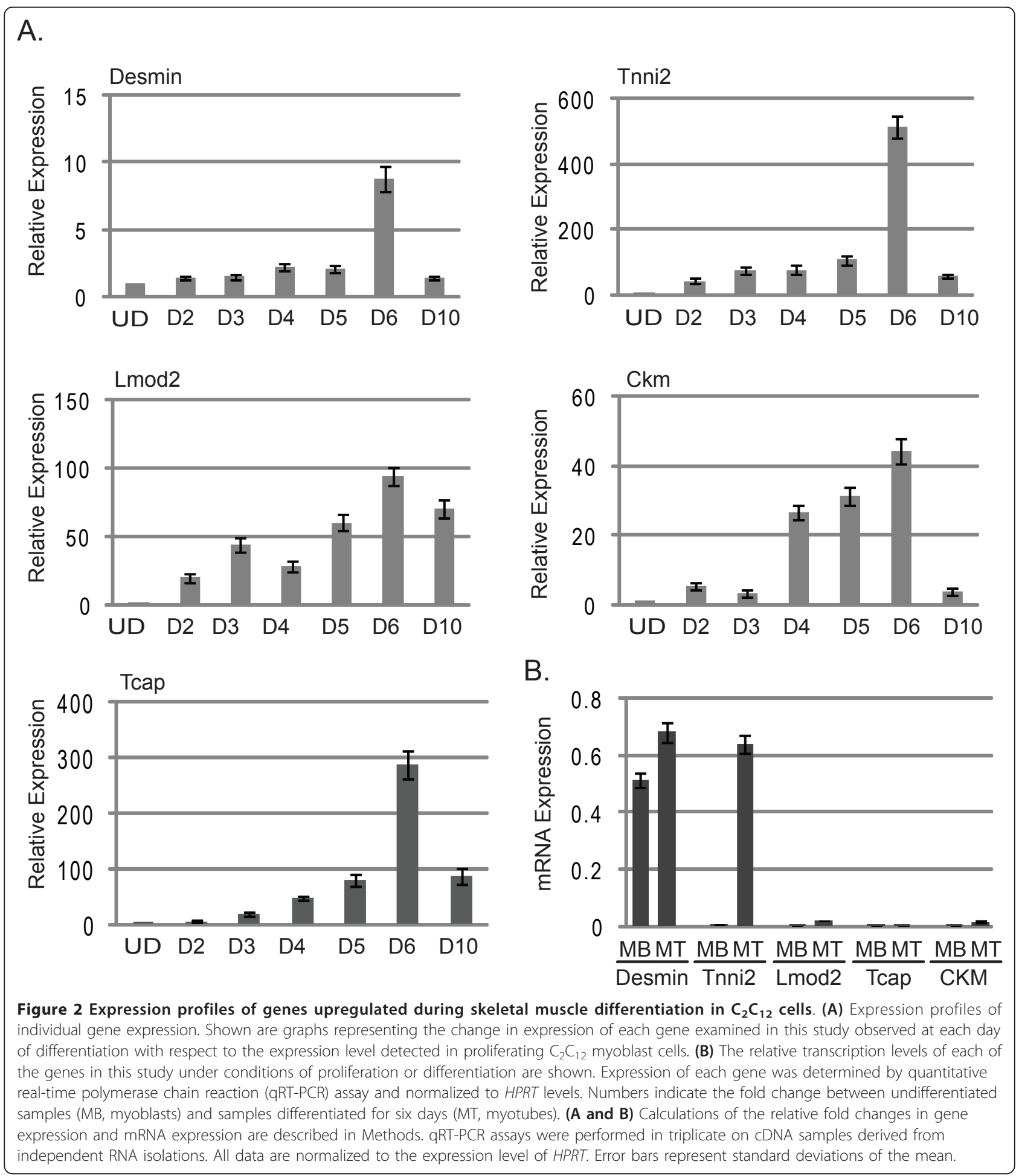

exception of $\operatorname{Lmod} 2$, after ten days in differentiation conditions. We also wanted to compare the relative expression levels of the chosen gene set. To perform this analysis, we compared the expression of each gene to a constitutive housekeeping gene, HPRT, in both proliferating myoblasts and differentiated myotubes
(Figure 2B). This analysis revealed that Des was expressed at a much higher level in proliferating myoblasts than any of the other genes examined in this study. We also observed that Tnni2 and Des were expressed at approximately the same high level in differentiated cells. The expression levels of $\operatorname{Lmod} 2, T c a p$ and 
$\mathrm{Ckm}$ increased significantly but did not reach the level of activation of Tnni2 or Des in this time course.

\section{Binding of MRFs and E proteins to muscle-specific genes}

Next, we profiled the binding of MyoD, myogenin, Myf5 and $E$ proteins over the time course of differentiation on each of these gene promoters. Proliferating cells and cells differentiated for one, two, three, six and ten days were used for the analysis. Surprisingly, we found that the pattern of recruitment was specific to each gene tested. First, we examined the well-characterized $\mathrm{Ckm}$ promoter [20-22]. For this analysis, we chose to examine the enhancer 1 element located upstream of the first noncoding exon of $\mathrm{Ckm}$ that contains one $\mathrm{E}$ box with the sequence CAGCTG, the preferred binding site for MyoD and myogenin. In accordance with recent chromatin immunoprecipitation sequencing (ChIP-seq) studies for MyoD [16], we did not detect MyoD at the $\mathrm{Ckm}$ enhancer in proliferating myoblasts (Figure 3). We also did not detect myogenin, Myf5 or HEB at this time point. After three days of differentiation, MyoD, myogenin and HEB were detectable at the $C \mathrm{~km}$ enhancer. However, six days after differentiation, we observed greatly enriched binding of HEB and myogenin compared to the relatively unchanged binding of MyoD. We also detected Myf5 at this enhancer at this time point. By ten days of differentiation, the MRFs and HEB appeared to be departing the promoter. While the binding was significantly enriched over background for all factors except MyoD, the levels at ten days of differentiation were greatly reduced from those observed at six days of differentiation. The dynamic profiles of the MRFs and E proteins were surprising to us, so we also compared the levels of RNAP II occupancy as a measure of transcriptional activity. As histone $\mathrm{H} 3$ acetylation is also a marker of active genes and increases in histone $\mathrm{H} 3$ acetylation are correlated with MyoD binding, we also examined the level of histone $\mathrm{H} 3$ acetylation at these promoters. For these assays, we compared the binding profile of RNAP II and acetylated histone $\mathrm{H} 3$ $(\mathrm{AcH} 3)$ at two days of differentiation and at six days of differentiation. We found that both RNAP II binding and histone $\mathrm{H} 3$ acetylation increased at six days of differentiation, consistent with the transcriptional profiling and the increased occupancy of all the MRFs and HEB.

At Des, the most robustly expressed gene examined in this study, we examined the previously characterized promoter proximal enhancer element [24]. This region immediately upstream of the transcriptional start site contains one E box with the sequence CAGCTG. We observed that MyoD bound to the Des promoter in proliferating cells, again consistent with the recent ChIP-seq study (Figure 4). MyoD remained bound to the promoter as the cells differentiated, with the binding ratio peaking at six days of differentiation. Myf5 and HEB were also present on the Des promoter in proliferating cells. A peak of Myf5 binding was observed after three days of differentiation, when a peak of myogenin binding was also detected. By six days of differentiation, Myf5 binding was still detectable, but at greatly reduced levels. The levels continued to decrease after ten days of differentiation. The level of HEB remained fairly constant during the first two days of differentiation, but began to increase after three days and steadily increased until six days of differentiation. HEB remained bound to the promoter after ten days of differentiation. Myogenin was not detected at the promoter in proliferating cells. Myogenin was detectable at the promoter after two days of differentiation, and its levels were greatly increased after three days of differentiation. The levels remained high at six days of differentiation. After ten days of differentiation, HEB levels remained relatively unchanged, but the binding ratios of the MRFs were greatly decreased. MyoD was no longer detected at the promoter, and only low levels of both myogenin and Myf5 remained associated with the promoter. We observed that RNAP II and AcH3 were associated with the promoter after two days of differentiation, and, surprisingly, those levels moderately decreased after six days of differentiation. We note that the relative fold enrichment of RNAP II and AcH3 was very high at Des, the most highly expressed gene in this study. This indicates that the number of Des promoters bound by RNAP II was much higher than what was observed at other promoters.

We next examined the Tnni2 promoter, which, like Des, is highly expressed in differentiating $\mathrm{C}_{2} \mathrm{C}_{12}$ cells (Figure 5). Previous work has shown that the expression of Tnni2 is highly dependent on myogenin in vivo [26]. The regulatory elements of Tnni2 are uncharacterized, so we chose to analyze a highly conserved noncoding sequence immediately upstream of the transcriptional start site. The transcriptional start site of Tnni2 is predicted to encode a short 5' untranslated region (5' UTR) that initiates $23 \mathrm{bp}$ prior to the translational start site. The conserved noncoding region is approximately $300 \mathrm{bp}$ upstream of the start of transcription and contains two $\mathrm{E}$ boxes. The sequence of the promoter distal $\mathrm{E}$ box is CACCTG, while the sequence of the promoter proximal E box is CAGCTG. The E boxes are separated by only $35 \mathrm{bp}$, so binding to either box could not be distinguished in our assay. As was true of Des, we observed an association of MyoD with the Tnni2 promoter in proliferating cells. The levels remained relatively unchanged during the time course of differentiation, although small variations were observed. Myf5 was recruited to the promoter upon the first day of differentiation, and the levels continued to increase until after day six. By day ten of 


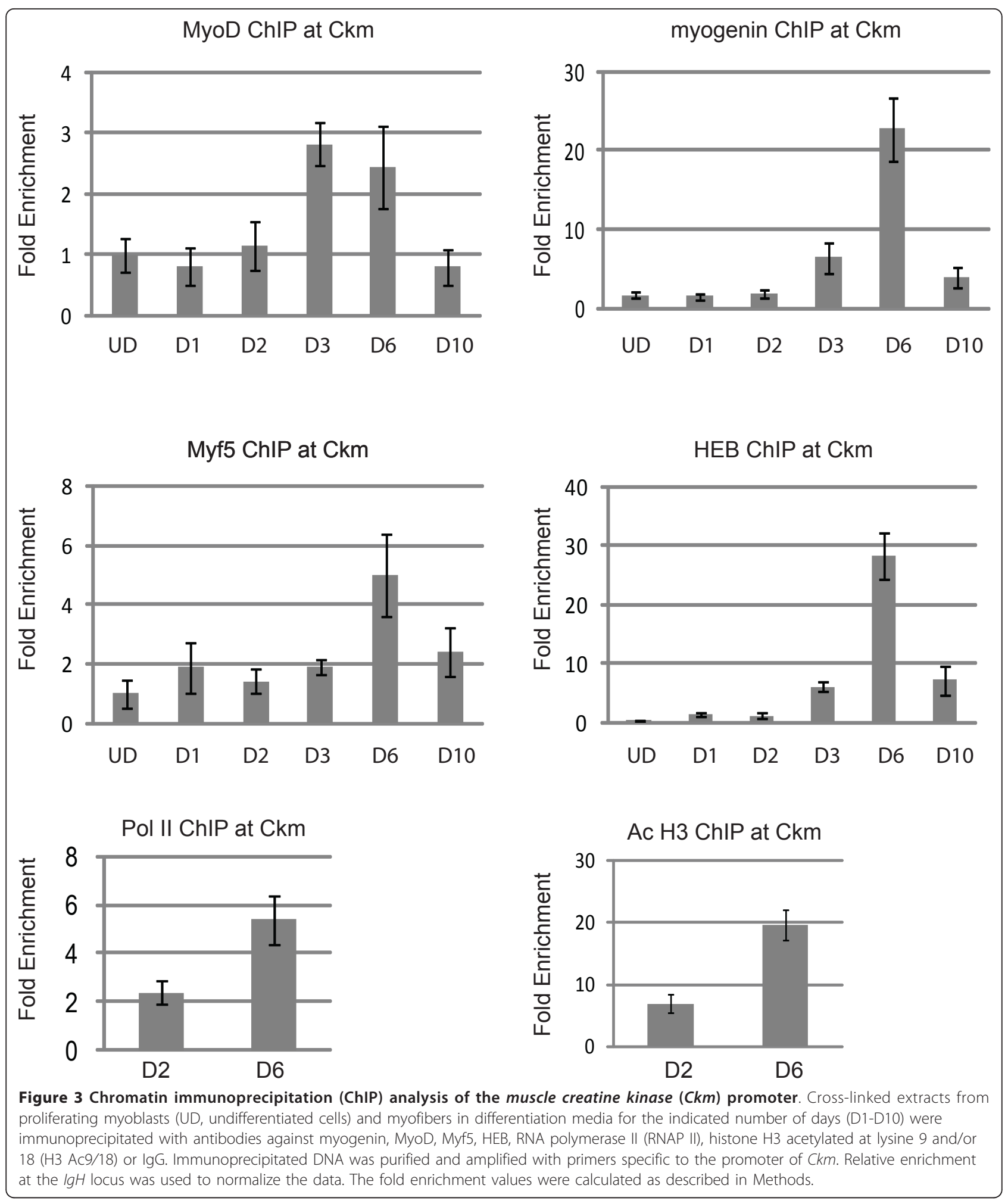

differentiation, Myf5 levels were greatly reduced. The recruitment of HEB was particularly surprising at this promoter. Here, we saw that HEB was not recruited to the promoter before two days of differentiation. The levels continued to increase at six days of differentiation, but binding rapidly declined after this point. At this promoter, the binding pattern of HEB completely overlapped with the binding pattern of myogenin. Myogenin could 


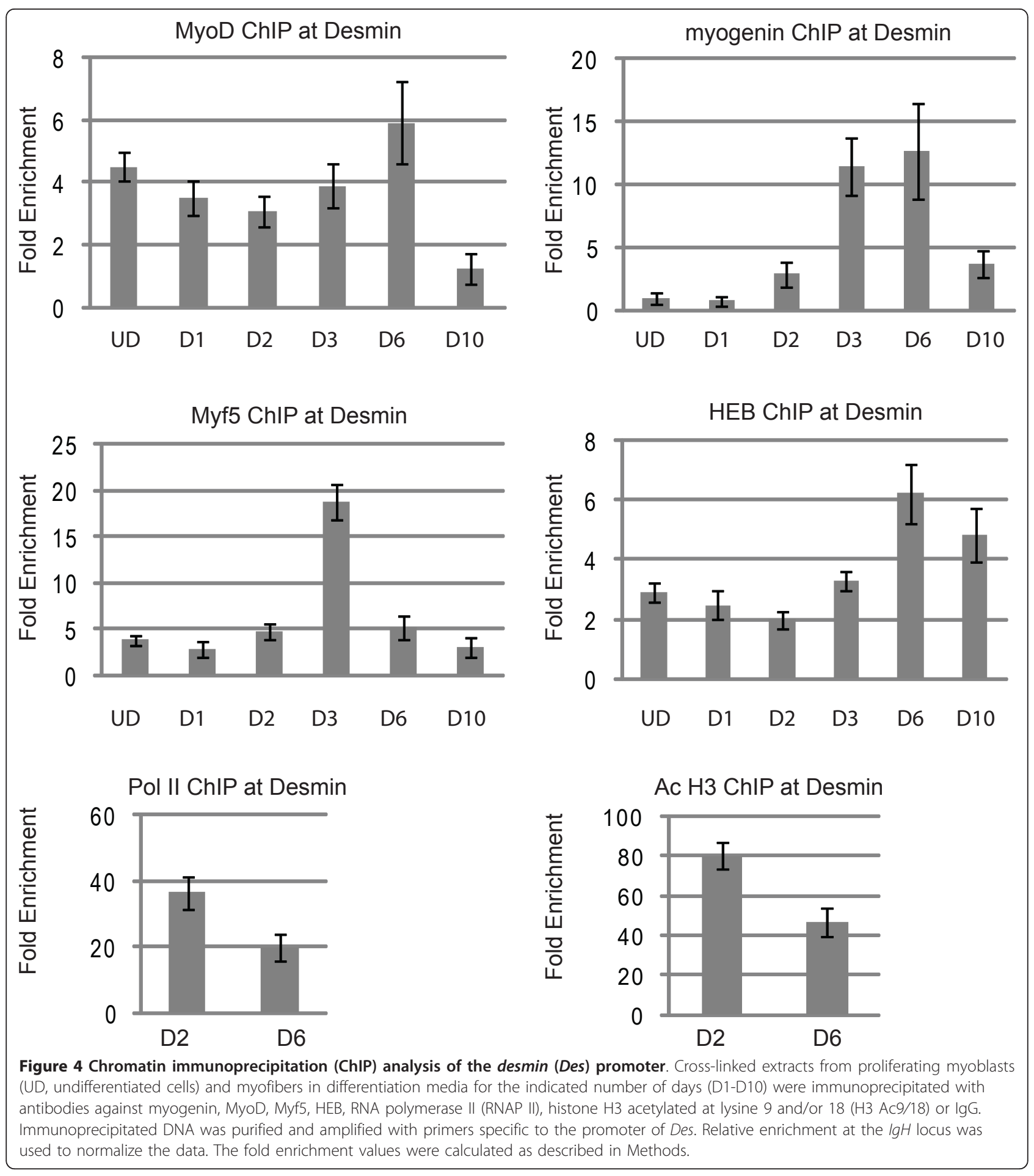

be detected at the promoter at two days of differentiation, but binding was greatly enhanced after three days of differentiation. The levels continued to increase at six days of differentiation, but rapidly decreased after this point. At Tnni2, we observed that while RNAP II and AcH3 were present at two days of differentiation, the levels significantly increased at six days of differentiation. After six days of differentiation, AcH3 levels reached the very high levels observed at Des.

The next promoter analyzed was the Lmod2 promoter (Figure 6). The expression of $\operatorname{Lmod} 2$ is dependent on myogenin during embryogenesis, and a promoter 


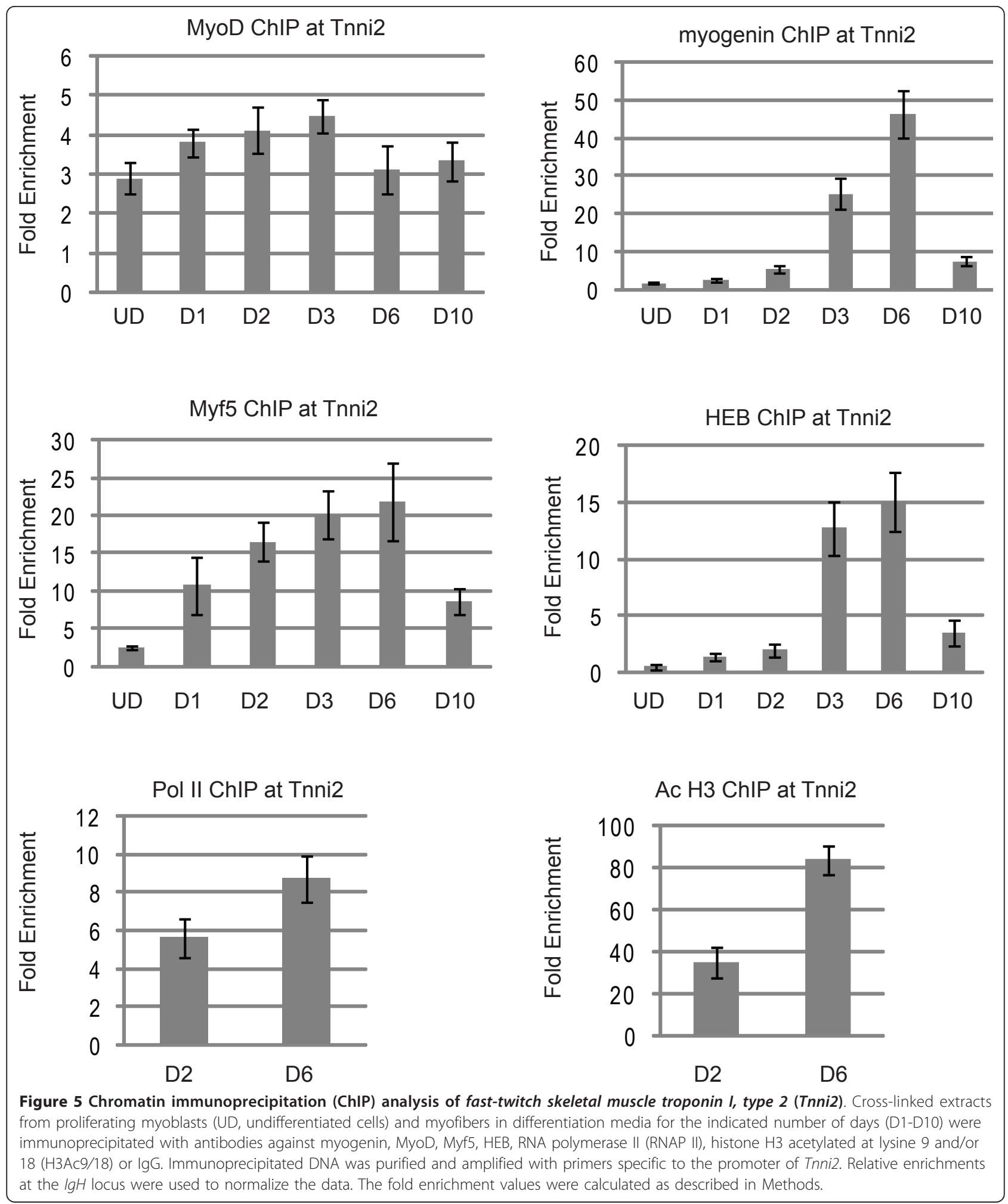

proximal binding site for myogenin has been defined [26]. A highly conserved noncoding region approximately 100 bp upstream of the predicted transcriptional start site contains two E boxes. The transcriptional start site of $\operatorname{Lmod} 2$ is immediately upstream of the translational start site, predicting a short 5' UTR of $112 \mathrm{bp}$. The sequence of the promoter proximal $\mathrm{E}$ box is CAGCTG, while the sequence of the promoter distal 


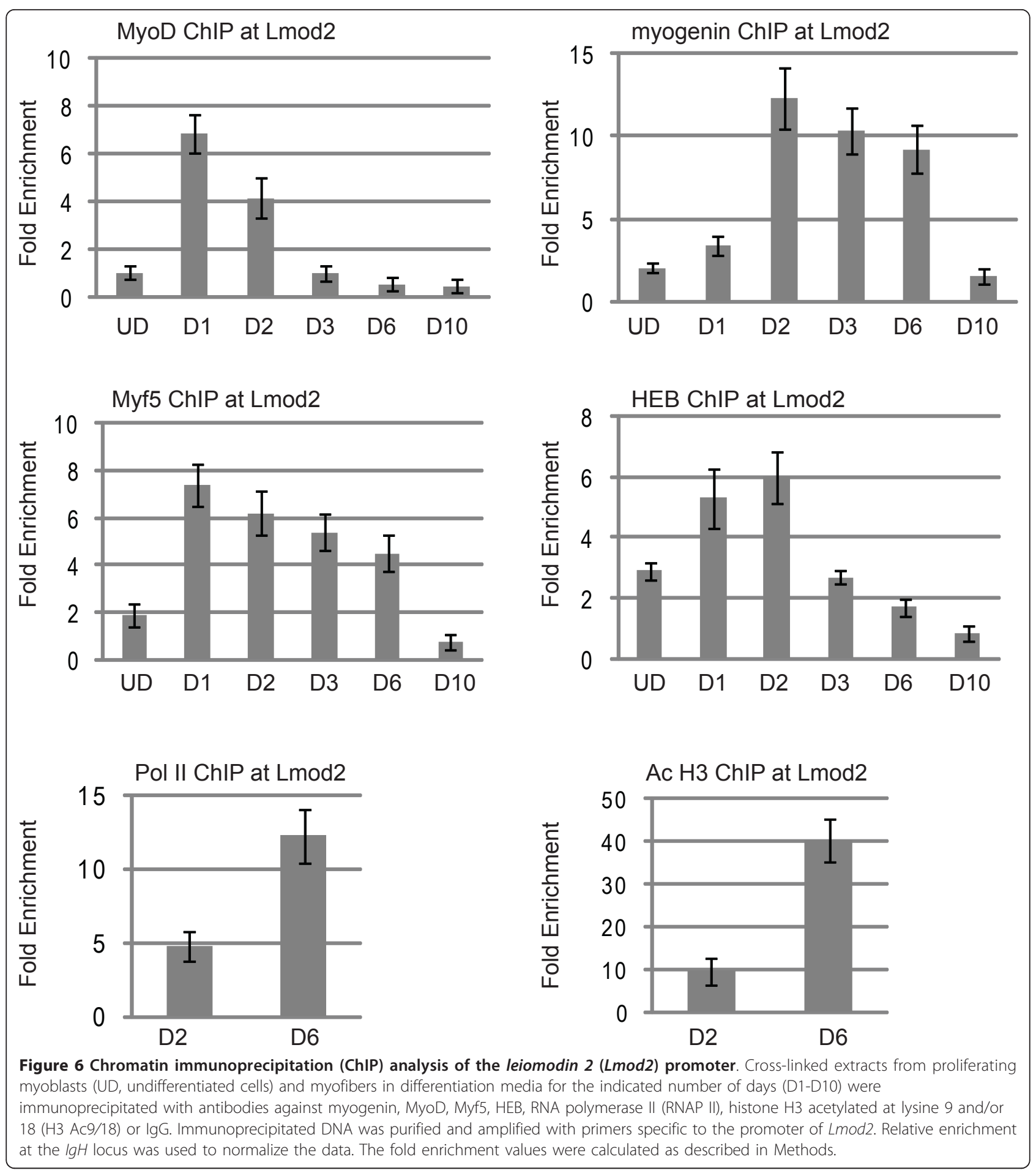

box E box is CAAATG. The E boxes are separated by $117 \mathrm{bp}$. Deletion of the promoter proximal E box in a luciferase reporter assay largely abolished the transactivation of the $\operatorname{Lmod} 2$ promoter by myogenin or MyoD [26]. At the Lmod2 promoter, we saw that HEB was present in proliferating cells, but none of the MRFs were significantly present. MyoD and Myf5 were recruited with a high affinity to the promoter on the first day of differentiation. Myogenin could be detected at this time point, but the binding ratio was relatively low. The association of myogenin increased greatly by two days of differentiation. Myogenin remained bound at six days of 
differentiation, but dissociated from the promoter by the tenth day of differentiation. MyoD and Myf5, recruited on the first day of differentiation, gradually dissociated from the promoter after this time point. MyoD was undetectable at three days of differentiation, while Myf5 remained associated with the promoter until sometime after six days of differentiation. The occupancy of HEB continued to increase during the initial stages of differentiation, peaking at two days of differentiation. HEB appeared to begin to dissociate from the promoter after two days of differentiation. HEB was only weakly detected at three days of differentiation and the levels continued to decrease at six days of differentiation, becoming undetectable by ten days of differentiation. The levels of RNAP II and AcH3 were significantly higher at six days of differentiation than at two days of differentiation.

The final promoter analyzed was the Tcap promoter (Figure 7). The Tcap locus contains a highly conserved promoter proximal noncoding sequence that contains two E boxes. Interestingly, neither the promoter proximal E box (CATCTG) nor the promoter distal E box (CATGTG) is a favored binding site for MyoD or myogenin. However, MyoD and myogenin can activate this promoter, and myogenin binds to the promoter during embryogenesis [27]. In proliferating cells, none of the MRFs or HEB is bound. At day one of differentiation, MyoD was recruited to the Tcap promoter. MyoD remained associated with the promoter until two days of differentiation, but dissociated from the promoter by three days of differentiation. This result is consistent with our promoter characterization of Tcap, as we have shown that the promoter proximal $\mathrm{E}$ box is required for both the activity in $C_{2} C_{12}$ cells and the activation by MyoD in NIH3T3 cells [27]. Myogenin was not recruited to the Tcap promoter at any time point tested, which was surprising to us, as we have detected myogenin binding to the Tcap promoter in skeletal muscle tissue during embryogenesis [27]. The profile of Myf5 was particularly surprising. Myf5 was not associated with the promoter at early stages of differentiation, but could be weakly detected at the promoter after six days of differentiation. This binding increased greatly by ten days of differentiation. HEB could be detected on the Tcap promoter after two days of differentiation, when MyoD was still present. However, by day three, MyoD had departed the promoter and the occupancy of HEB increased greatly at this time. The peak of HEB binding appears to occur at three days of differentiation. By day six, HEB was at the same low level observed at two days of differentiation, and by ten days of differentiation it was undetectable. We found the pattern of MRF and HEB association at this gene particularly interesting, as there is almost no overlap between these factors. MyoD was recruited, followed by HEB, which then dissociated as Myf5 arrived. At this promoter, we again observed that RNAP II occupancy and H3 acetylation greatly increased at six days of differentiation as compared to two days of differentiation.

\section{HEB replaces E12/E47 at specific promoters during differentiation}

At each of these promoters, we found the distinct pattern of HEB binding very surprising. We had anticipated seeing HEB bound to the promoter whenever an MRF was bound. While there are overlaps, the pattern of HEB binding is temporally controlled and unique to each gene. We wondered if perhaps these findings could be the result of the binding of the $E 2 A$ gene products E12 or E47 in a compensatory fashion. We reasoned that $\mathrm{E}$ proteins might be associated at all time points, but the E protein could be either E12/E47 or HEB. To address this hypothesis, we repeated the ChIP assays on proliferating cells, on cells differentiated for two days and on cells differentiated for three days with antibodies against the $E 2 A$ gene products. In proliferating cells, E12 or E47 could be detected at the Des and Lmod2 promoter binding sites (Figure 8A). For Lmod2, the binding of E12/E47 was detected with HEB in proliferating cells, but E12/E47 was lost as cells began to differentiate while HEB levels increased (Figure 8B). At two days of differentiation, E12/E47 could still be detected at the Des promoter, but that binding was lost at three days of differentiation (Figure $8 \mathrm{C}$ ). At both of these promoter binding sites, we observed an exchange of E12/ E47 and HEB as cells began to differentiate. E12/E47 was not detected on any of the other promoters assayed in this study. We have analyzed additional promoter proximal elements of differentiation-specific genes and have found that E12/E47 was associated with the myogenin(myog), troponin C, type 2(Tnnc2) and myosin heavy chain 3 (Myh3) promoters in undifferentiated cells as well (Additional file 1 Figure S5A). We did not observe an association with the troponin $T$, type 2 (Tnnt2) promoter. In each case, binding was lost by two days of differentiation (data not shown). HEB was observed on the Tnnt2, Myh3 and Tnnc2 promoters following two days of differentiation (Additional file 1 Figure S5B). For the majority of the promoters analyzed here, it appears that HEB is the predominant $\mathrm{E}$ protein recruited during differentiation and that the transient association of HEB is not compensated by an overlapping pattern of E12/E47. These data are consistent with previously reported data that have established an important role for HEB $\beta$ in inducing differentiation [15]. Next, we asked whether the presence of HEB is required to displace E12/E47 from promoters as cells begin to differentiate. HEB levels were depleted with small 


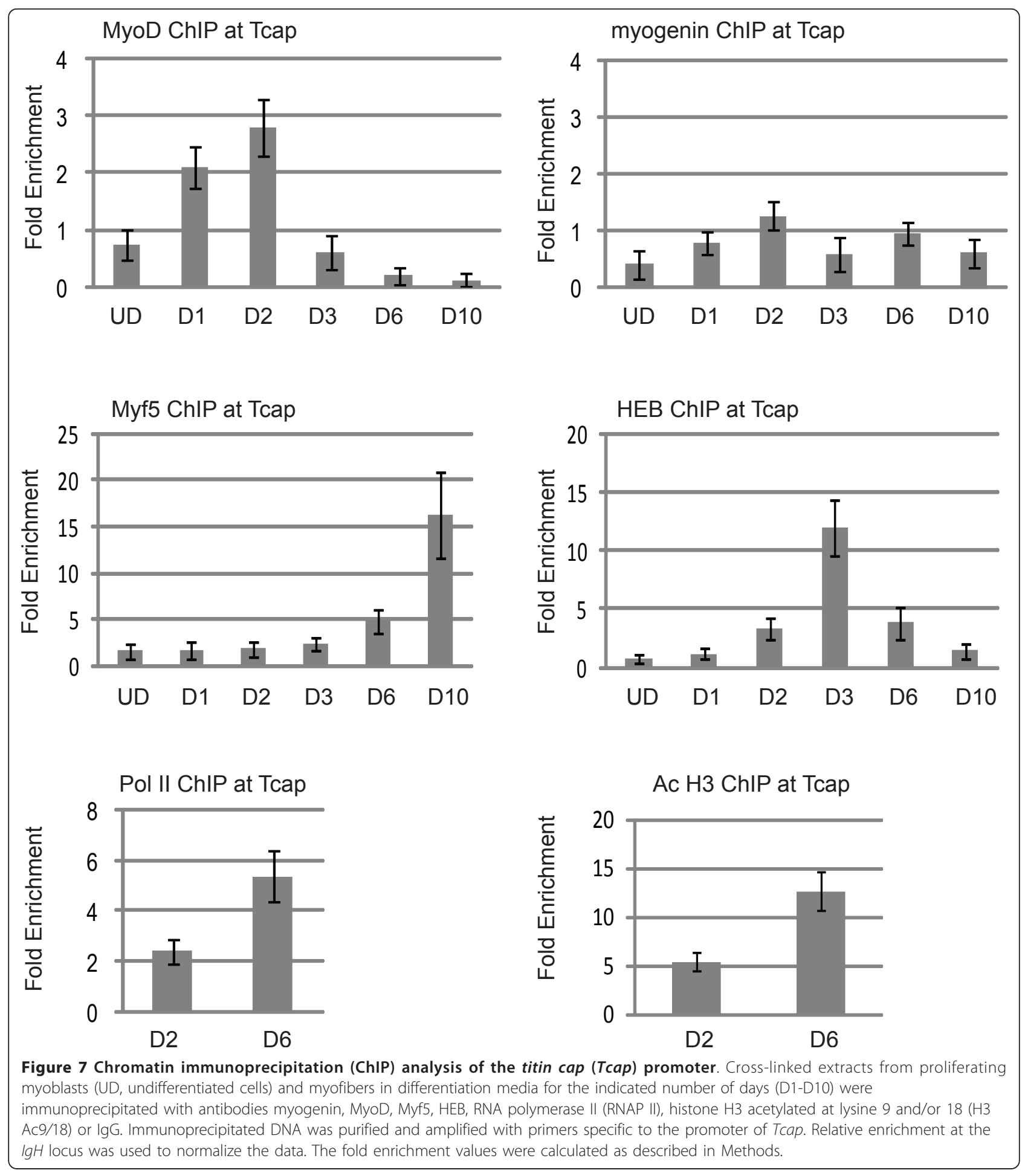

hairpin (shRNA) constructs targeting HEB. Stable cell lines expressing these constructs were screened for expression of HEB and E12/E47. We proceeded with a construct that showed a $73 \%$ knockdown of HEB expression by RNA analysis (Figure 8D) and a reduction in protein expression by Western blot analysis (Figure
8E). No change in E12/E47 expression was detected by gene expression analysis (data not shown). ChIP assays with antibodies against E12/E47 were performed on cells differentiated for two days. We saw no enhanced association of E12/E47 in cells reduced in expression of HEB (Figure 8F), indicating that HEB is not required for 
A.

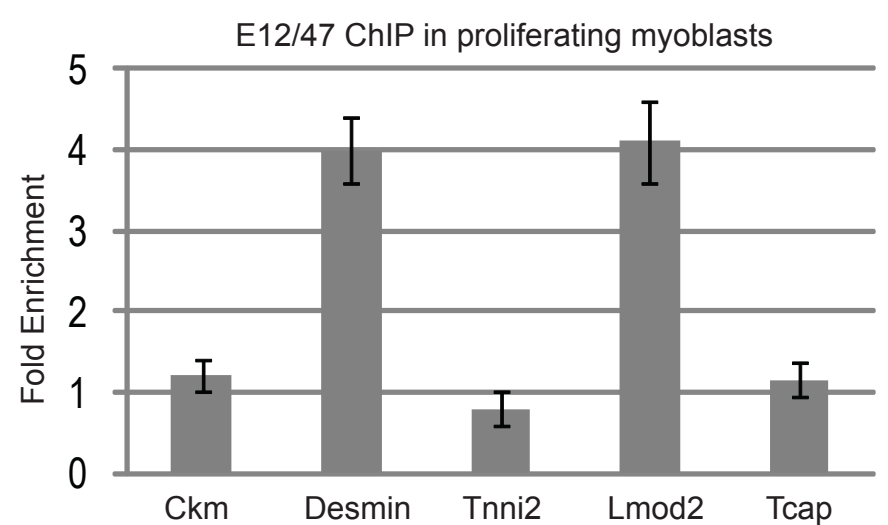

B.

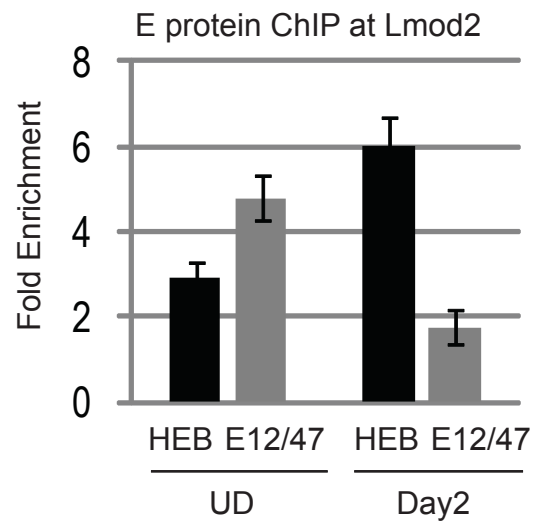

D.
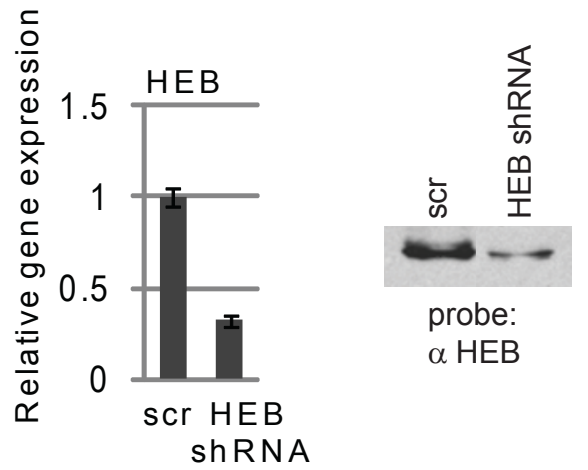

C.

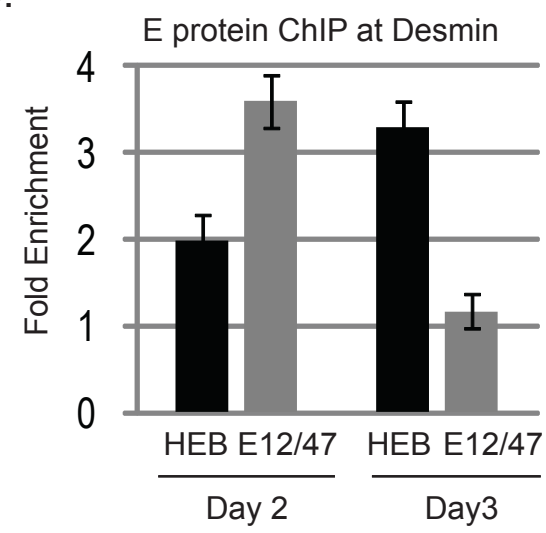

$\mathrm{F}$.

E12/47 ChIP in myotubes (D2)

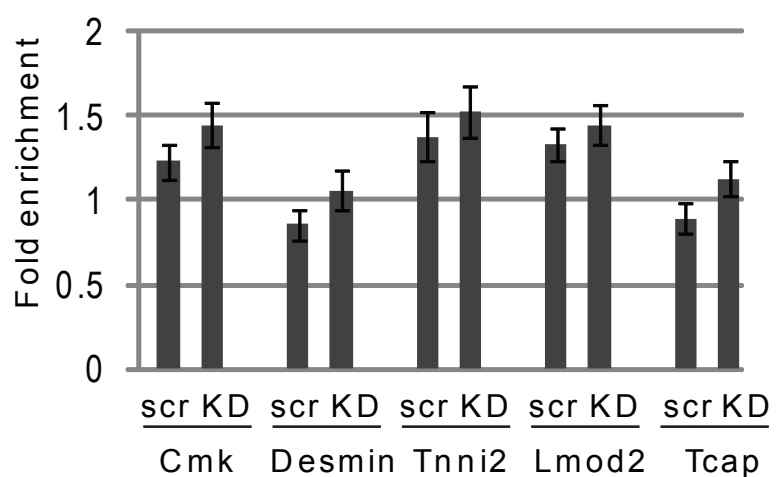

Figure 8 E12/E47 and HEB exchange at the leiomodin 2 (Lmod2) and desmin (Des) promoters. (A) E12/E47 binds to the promoters of Des and $L \bmod 2$ in myoblasts. Cross-linked extracts from proliferating myoblasts (UD, undifferentiated cells) were immunoprecipitated with antibodies against the E2A gene products. Immunoprecipitated DNA was purified and amplified with primers specific to the promoters of Ckm, Des, Tnni2, Lmod2 and Tcap. (B) E12/E47 and HEB exchange at the Lmod2 promoter. Cross-linked extracts from proliferating myoblasts and myofibers in differentiation media for two days were immunoprecipitated with antibodies against the E2A gene products, HEB or IgG. Immunoprecipitated DNA was purified and amplified with primers specific to the promoter of Lmod2. (C) E12/E47 and HEB exchange at the Des promoter. Crosslinked extracts from myofibers in differentiation media for two or three days were immunoprecipitated with antibodies against the E2A gene products, HEB or lgG. Immunoprecipitated DNA was purified and amplified with primers specific to the promoter of Des. Relative enrichment at the $\mathrm{lgH}$ locus was used to normalize the data. The fold enrichment values were calculated as described in Methods. (D) Gene expression analysis of HEB in cells expressing a small hairpin RNA (shRNA) construct targeting HEB or a scrambled control (scr). (E) Western blot analysis of the cells described in Figure 8D. The Western blot was probed with antibodies against HEB. (F) HEB is not required to displace E12/E47 at promoters. Results of chromatin immunoprecipitation assays performed after two days of differentiation on HEB-depleted cells and the scr control are shown. 
the displacement of E12/E47 from promoters during differentiation.

\section{Myogenin, MyoD and Myf5 co-occupy promoters}

We were particularly interested in the binding profile of Myf5. For each gene tested, Myf5 had a unique binding pattern that was distinct from the binding patterns of MyoD and myogenin. We were surprised to observe that the profile of Myf5 overlapped with myogenin at several genes. To understand whether Myf5 and myogenin also colocalized during embryonic muscle development, we repeated the ChIP experiments in skeletal muscle tissue derived from embryonic day 18.5 (E18.5) embryos. We chose E18.5 as it is late in embryogenesis and is a time point at which myogenin is assumed to be highly active. Myf5 is known to function only during the early stages of myogenesis and thus would not be expected to contribute to gene expression at this stage. Moreover, Myf5 transcripts are not observed in embryos after E14 [28]. However, we detected Myf5 protein in hindlimb samples at late embryonic stages (Additional file 1 Figure S6). As expected, we detected myogenin at several muscle-specific promoters, including $\operatorname{Lmod} 2$ and Des (Figure 9A). Consistent with our $\mathrm{C}_{2} \mathrm{C}_{12}$ data, Myf5 colocalized with myogenin at both of these promoters in vivo (Figure 9A). After confirming that myogenin and Myf5 appear to bind to the same sequences at a late time point in embryogenesis, we were very interested in understanding whether the overlapping pattern was occurring in two cell populations or whether Myf5, myogenin and MyoD co-occupy promoters. To address this question, we performed sequential ChIP(ChIP-seq) assays for myogenin, MyoD and Myf5 in $\mathrm{C}_{2} \mathrm{C}_{12}$ cells. To address whether Myf5 and myogenin co-occupy promoters, cells were differentiated for three days, immunoprecipitated with Myf5 antibodies and subsequently immunoprecipitated with antibodies against myogenin. We detected co-occupancy of Myf5 and myogenin at the Tnni2 and Des promoters (Figure 9B). We also performed the experiment with antibodies against myogenin first, followed by immunoprecipitation with Myf5 antibodies, and, again, co-occupancy of Myf5 and myogenin on the Tnni2 and Des promoters was confirmed (data not shown). We next assayed for co-occupancy of MyoD and myogenin. Cells were differentiated for three days, immunoprecipitated with antibodies against MyoD and subsequently immunoprecipitated with antibodies against myogenin. Again, we observed co-occupancy of MyoD and myogenin on the Des and Tnni2 promoters (Figure 9B). Finally, we asked whether Myf5 and MyoD co-occupy promoters. Differentiated cell extract was immunoprecipitated with antibodies against Myf5 and subsequently immunoprecipitated with antibodies against MyoD. We observed that Myf5 and MyoD co-occupied the Des and Tnni2 promoters (Figure 9B). These data confirm that MyoD, myogenin and Myf5 are bound to the same promoter elements.

\section{Discussion}

We have found that each muscle gene assayed showed a unique temporal association of the MRFs and E proteins. We were surprised to observe the dynamic and transient roles of the MRFs on each of these promoters. MyoD has been proposed to be a "pioneer" transcription factor required to initiate the cascade of regulatory events required to initiate expression of muscle-specific genes [29]. MyoD recruits chromatin-modifying activities that alter both the regional histone modifications and the chromatin remodeling at promoter binding sites $[7,30]$. It is thought that these events then allow the subsequent binding and transcriptional activity of myogenin. Our data are consistent with this model, as we observed early associations of MyoD followed by the association of myogenin. Our gene expression data also show that for most genes examined in this study, the recruitment of myogenin is coincident with high levels of transcription. Our data are consistent with those reported in other studies that showed that at the genes whose expression marks late myogenesis, $\mathrm{Ckm}$ and Des, MyoD is bound first, followed by the appearance of myogenin, Mef2 (myocyte enhancer factor 2) and Brg1 (Brahma-related gene 1), the catalytic subunit of the Swi/Snf chromatin remodeling complex [25]. In this prior study, it was also shown that the recruitment of myogenin was coincident with high levels of transcription of these genes in embryonic tissue. In our study, the peak of transcription and myogenin binding correlated with high levels of RNAP II promoter occupancy and histone $\mathrm{H} 3$ acetylation at the majority of genes assayed. We note that the histone $\mathrm{H} 3$ acetylation levels continued to rise following the departure of MyoD at several genes. These data suggest that while MyoD may be the initiating factor for chromatin modifications at the promoter, the continued presence of MyoD is not required for further increases in histone $\mathrm{H} 3$ acetylation.

The pattern of Myf5 binding was highly surprising. On certain genes, the Myf5 binding pattern overlapped with MyoD, but at other genes, the binding pattern overlapped with myogenin. In each case, the binding profile of Myf5 suggests that Myf5 has a previously uncharacterized role in mediating gene expression in differentiating cells. While it is known that Myf5 cannot mediate differentiation without myogenin or MyoD [8], our data suggest that Myf5 does cooperate with both MyoD and myogenin. Other groups have suggested that $C_{2} C_{12}$ cells, or the $\mathrm{C}_{2}$ cells used to derive them, have two populations of myoblasts: a MyoD-expressing population thought to be the differentiating population and a 
A.

E18.5 ChIP at Lmod2

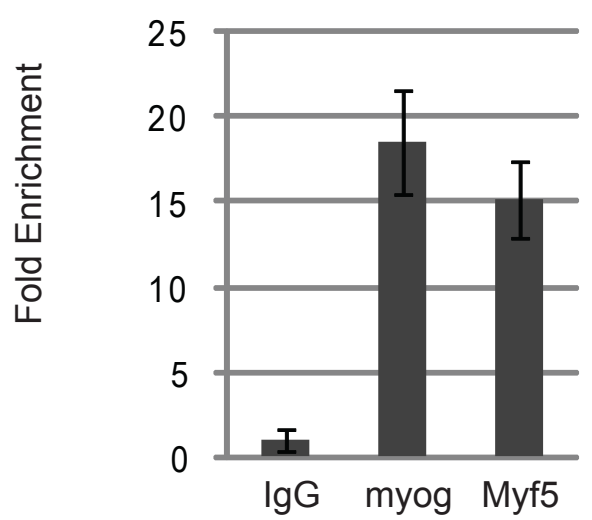

E18.5 ChIP at Desmin

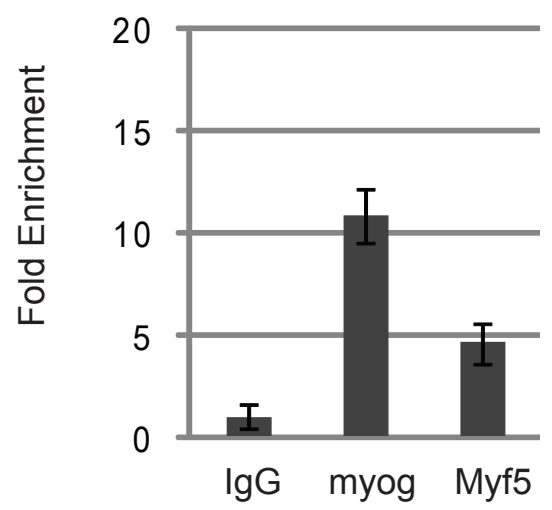

B.

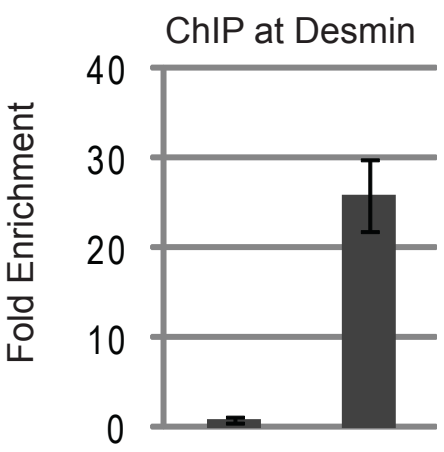

1st IP: $\quad \lg$ Myf5

2nd IP: myog myog
ChIP at Desmin

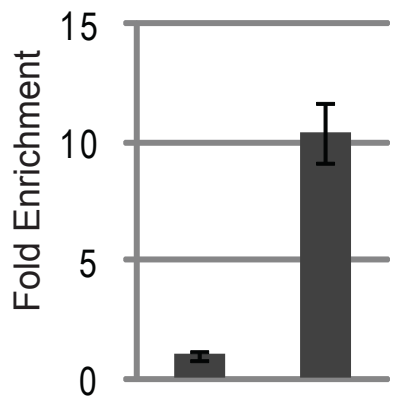

1st IP: IgG MyoD

2nd IP: myog myog

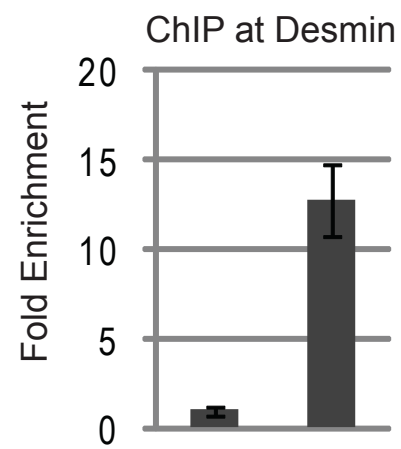

1st IP: $\lg$ Myf5

2nd IP: MyoD MyoD
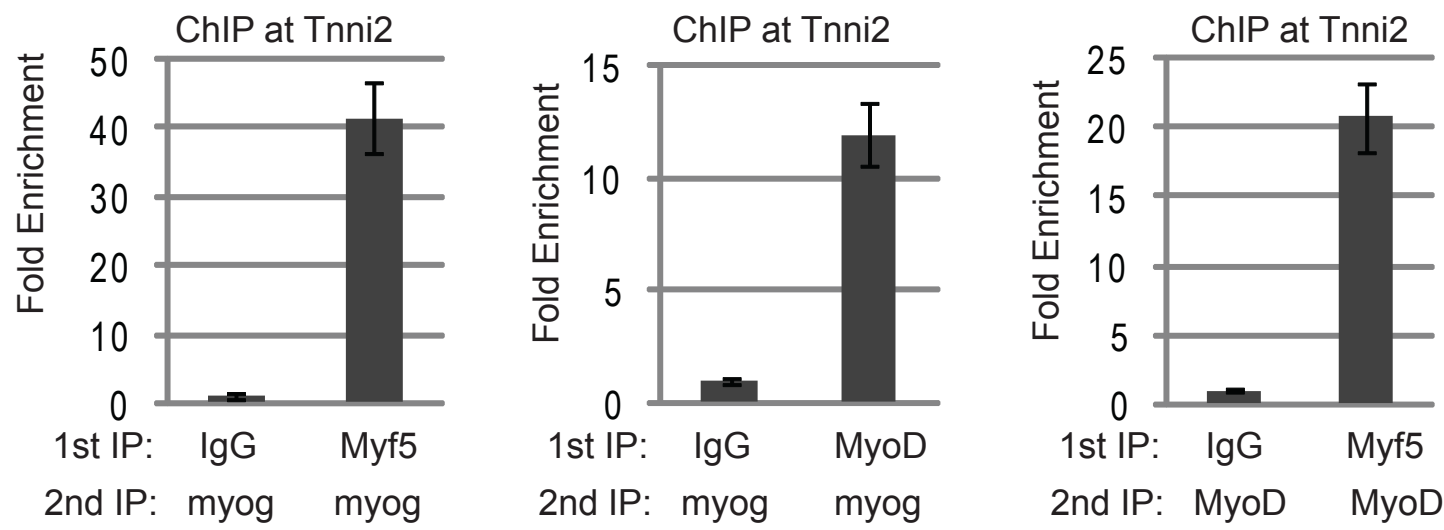

Figure 9 Myogenin and Myf5 colocalize in vivo and co-occupy promoters with MyoD. (A) Myf5 and myogenin colocalize on promoters during embryonic development. Chromatin immunoprecipitation (ChIP) analysis was performed on skeletal muscle from E18.5 embryos. The immunoprecipitated DNA was purified and amplified with primers specific to the promoter of leiomodin 2 (Lmod2) and desmin (Des). The fold enrichment values were calculated as described in Methods. (B) Myf5, myogenin and MyoD co-occupy promoters. Cross-linked extracts from myofibers in differentiation media for two days were immunoprecipitated with antibodies against the indicated antibody (1st IP) or lgG. The immunoprecipitated complexes were released and immunoprecipitated again with antibodies against the indicated antibody (2nd IP). The immunoprecipitated DNA was purified and amplified with primers specific to the promoters of Tnni2 and Des. Relative enrichment at the $1 g \mathrm{H}$ locus was used to normalize the data. The fold enrichment values were calculated as described in Methods. 
nondifferentiating or reserve population that expresses Myf5 [31,32]. However, in our studies, we can conclude that Myf5 is expressed in differentiating cells and that it colocalizes with MyoD and myogenin on specific promoters in $\mathrm{C}_{2} \mathrm{C}_{12}$ cells. Our data are highly suggestive that Myf5 plays a role in differentiation, but additional experiments are required to confirm this hypothesis.

The binding pattern of myogenin was surprising as well. The association of myogenin with muscle-specific genes as cells began to differentiate was expected, as myogenin is greatly upregulated at this time. However, the relatively brief association of myogenin with target genes was unexpected. A transient role of myogenin on target genes has previously been suggested, as myogenin appears to have distinct target gene sets during embryogenesis and in adult satellite cells and adult tissue $[26,33]$. Our data suggest that myogenin may mediate changes at the promoter that maintain high levels of expression without the continued presence of myogenin. Candidates for such a change include the switching of core promoter complexes, which has been observed in skeletal muscle differentiation. A TATA-binding protein (TBP)-related factor, TRF3, and an associated TBP-associated factor, TAF3, have been shown to be targeted by MyoD to the myogenin promoter following differentiation $[31,34]$. TBP is expressed in proliferating myoblasts, but following differentiation, TBP is downregulated and TRF3 and TAF3 are upregulated. It is also possible that myogenin may direct epigenetic changes that maintain gene expression.

The binding pattern of HEB was very surprising to us as well. Detailed biophysical experiments have shown that MRF and E protein heterodimers are highly stable when bound to DNA. These studies have also indicated that heterodimers likely form on the DNA. MyoD and E47 heterodimers are not detected in diluted conditions without DNA. However, in the presence of DNA, heterodimeric complexes are formed almost exclusively [35]. Additional work has shown that the weak MyoD homodimers and heterodimers that can form in the absence of DNA are equally stable [36]. This suggests that the MRFs and E proteins are likely to be monomeric in the cell. In this work \{Maleki, $2002 \# 376$ \}, it was also shown that while MyoD or myogenin E protein heterodimers on DNA were the most energetically favorable, MyoD and myogenin homodimers can bind E boxes with considerable positive cooperativity, while E12 homodimers exhibited negative cooperativity. The negative cooperativity of E12 suggests that the heterodimer may form on DNA by binding of the E12 monomer followed by binding of the MRF monomer.

Given these data, we anticipated detecting E proteins on the DNA throughout the time course of differentiation. Instead, we found a highly dynamic pattern of recruitment and release of HEB. This pattern was not compensated by E12/E47, as we observed E12/E47 binding to only two of the promoters in this study at early time points. At three days of differentiation, E12/E47 was not detected at any of the promoters analyzed. At Des, the only gene highly expressed during proliferation examined in this study, we did observe an association with both E12/E47 and HEB in proliferating cells. At Lmod2, we also observed an early recruitment of E12/ E47 and HEB, whereas we observed only late recruitment of HEB at genes such as Tnni2. We hypothesize that E12/E47 might be required at a subset of genes whose expression is immediately required as cells begin to differentiate. While $\operatorname{Lmod} 2$ is not significantly expressed in proliferating cells, Lmod2 is upregulated very rapidly upon differentiation, and while the expression does continue to increase over an extended time course, the expression increases only two fold. This is in contrast to genes such as Tnni2, where the expression level increases ten fold over the extended time course. Lmod2 does not reach the high levels of transcription seen at Tnni2 that coincide with the peak of HEB binding. It is possible that the early recruitment of E12/E47 and HEB at $\operatorname{Lmod} 2$ helps to support a relatively constant level of expression that initiates immediately upon differentiation. It is striking that at both genes where we observed the binding of E12/E47, we also observed that HEB appeared to replace E12/E47 as cells began to differentiate. The binding pattern of HEB at Tcap is particularly interesting. HEB binding peaks at a time point when no MRFs are detected. Reduced levels of binding are detected at two additional time points when MyoD and Myf5 are bound on the individual days. Thus, while the HEB binding profile does overlap with MRF binding as predicted by the biophysical studies, the occupancy of HEB does not always overlap with the occupancy of the MRFs.

While these data have revealed many novel findings regarding the recruitment of the MRFs and E proteins, many questions remain. The additional factors and DNA elements that mediate the individual recruitment and release of each of these factors remain to be characterized. Many elegant studies of the role of chromatin modification in muscle differentiation have suggested that epigenetic events are important mediators in the activation of muscle genes. The Swi/Snf chromatin remodeling complex promotes muscle differentiation, and it is known that the Swi/Snf complex is recruited to both the Des and Ckm promoters studied here [25,37]. Important questions for future studies include how chromatin remodelers and chromatin-modifying enzymes contribute to the recruitment and release of the myogenic regulatory factors and $\mathrm{E}$ proteins to regulate muscle gene expression. 


\section{Conclusions}

Here we have shown that MyoD, myogenin and Myf5 have sequential and transient roles on each of the promoters assayed. For almost every gene assayed, we found that the binding of myogenin and HEB correlated with high levels of RNAP II occupancy, histone H3 acetylation and the peak of transcription as assayed by mRNA levels. We found that the primary E protein recruited to late differentiation genes is HEB. At the few promoters where E12/E47 was detected at early stages, HEB replaced E12/E47 during differentiation. Finally, we have shown that MyoD, myogenin and Myf5 colocalize on promoters, suggesting that Myf5 contributes to the gene expression of late differentiation genes.

\section{Methods}

\section{Cell culture}

Cells were grown in a humidified chamber at $37^{\circ} \mathrm{C}$ with $5 \% \mathrm{CO}_{2}$. Proliferating $\mathrm{C}_{2} \mathrm{C}_{12}$ myoblasts (American Type Culture Collection, Manassas, VA, USA) were grown in Dulbecco's modified Eagle's medium (DMEM) supplemented with $10 \%$ fetal bovine serum (Thermo Scientific HyClone, Logan, UT USA. To induce differentiation into myotubes, cells were grown to $70 \%$ confluence and media were switched to DMEM supplemented with $2 \%$ horse serum (Thermo Scientific HyClone, Logan, UT USA). $\mathrm{C}_{2} \mathrm{C}_{12}$ cells were grown in differentiation medium for the number of days indicated in each experiment.

\section{Western blot analysis}

Cell extracts were made by lysing phosphate-buffered saline-washed cell pellets in radioimmunoprecipitation assay buffer supplemented with protease inhibitors (Complete Protease Inhibitor Cocktail Tablets; Roche Applied Science, Indianapolis, IN USA. Following incubation on ice, clear lysates were obtained by performing centrifugation. Protein concentrations were determined by using the Bio-Rad Protein Assay (Bio-Rad, Hercules, CA USA. For each sample, $30 \mu \mathrm{g}$ of protein were loaded onto each gel. Proteins were transferred onto a nitrocellulose membrane using a tank blotter (Bio-Rad, Hercules, CA USA), then blocked using $5 \%$ milk and $1 \times$ Tris-buffered saline plus Tween 20 (TBST) and incubated with primary antibody overnight at $4{ }^{\circ} \mathrm{C}$. Membranes were then washed with $1 \times$ TBST and incubated with the corresponding secondary antibody. Membranes were again washed with $1 \times$ TBST, incubated with chemiluminescence substrate according to the manufacturer's protocol (SuperSignal West Pico Chemiluminescent Substrate; Pierce Biotechnology, Rockford, IL USA and visualized by autoradiography. The antibodies used include antiHEB (A-20; Santa Cruz Biotechnology, Santa Cruz, CA, USA), anti-E12/E47 (Yae; Santa Cruz Biotechnology),
anti-Myf5 (C-20; Santa Cruz Biotechnology), anti-MyoD (5.8A; Santa Cruz Biotechnology), anti-GAPDH (anti-glyceraldehyde 3-phosphate dehydrogenase; Chemicon International, Billerica, MA USA) and anti-MyoG (F5D).. The F5D antibody developed by W. E. Wright was obtained from the Developmental Studies Hybridoma Bank under the auspices of the NICHD and maintained by the University of Iowa, Department of Biology, Iowa City, IA USA. Normal rabbit immunoglobulin G (IgG) (Santa Cruz Biotechnology, Santa Cruz, CA USA) was used as a nonspecific control.

\section{Quantitative reverse transcriptase-polymerase chain reaction assays}

RNA was isolated from $\mathrm{C}_{2} \mathrm{C}_{12}$ cells by TRIzol reagent extraction (Invitrogen, Carlsbad, CA. Two micrograms of total RNA were reverse-transcribed with MultiScribe $^{\mathrm{TM}}$ Reverse Transcriptase (Applied Biosystems, Carlsbad, CA USA. cDNA equivalent to $40 \mathrm{ng}$ was used for quantitative reverse transcriptase-polymerase chain reaction (qRT-PCR) amplification (Applied Biosystems, Foster City, CA USA) with SYBR Green PCR Master Mix (Applied Biosystems, Foster City, CA USA). Samples in which no RT was added were included for each RNA sample. For measurements of relative gene expression, a fold change was calculated for each sample pair and normalized to the fold change observed at HPRT. mRNA expression levels were quantitated using a calibration curve based on known dilutions of concentrated cDNA. Each mRNA value was normalized to that of $H P R T$. Fold change was calculated by dividing the mRNA expression values of each sample pair. qRT-PCR data were calculated using the comparative $C_{\mathrm{t}}$ method (Applied Biosystems, Foster City, CA USA). Standard deviations from the mean of the $\Delta C_{\mathrm{t}}$ values were calculated from three independent RNA samples and used to generate error bars. Intron-spanning primers to the coding region of Lmod2, Des, Tnni2, Ckm and Tcap are described in Additional file 1 Table S1. All qPCR assays were performed in triplicate, and at least two independent RNA samples were assayed for each time point.

\section{ChIP assays}

Cell culture ChIP assays were performed and quantified as described previously [38] with the following modifications: $1 \times 10^{7}$ cells were used for each immunoprecipitation, and protein A agarose beads (Invitrogen) were used to immunoprecipitate the antibody-antigen complexes. ChIP assays of embryonic tissue were performed as previously described [26]. Limb tissue from wild-type C57BL/6 mice\{Jackson Laboratory, Bar Harbor, ME USA) was isolated, cross-linked and enriched for nuclei. Nuclear extracts of limb tissue were precleared using 
incubation with protein A agarose beads (Invitrogen, Carlsbad, CA USA), which were also used to immunoprecipitate the antibody complexes from tissue extracts following antibody addition to the incubation mix. Antibodies against the following proteins were used: MyoD (5.8A; Santa Cruz Biotechnology, Santa Cruz, CA USA), HEB (A-20; Santa Cruz Biotechnology, Santa Cruz, CA USA), Myf5 (C-20; Santa Cruz Biotechnology, Santa Cruz, CA USA), E proteins (Yae; Santa Cruz Biotechnology, Santa Cruz, CA), myogenin (F5D; Developmental Studies Hybridoma Bank), RNAP II (H-224; Santa Cruz Biotechnology, Santa Cruz, CA USA) and histone H3 acetylated at lysine 9 and/or 18 (H3.Ac9/18; Millipore, Billerica, MA USAUpstate Biotechnology. Primers spanning the described promoter elements of Lmod2, Des, Tnni2, Ckm, Tcap, Myog, Tnnt2, Myh3 and Tnnc2 are described in Additional file 1 Table S1. $2^{-[\Delta][\Delta] C t}$ values were calculated using the following formula based on the comparative $C_{\mathrm{t}}$ method: $\Delta C_{\mathrm{t}}$, template (antibody) $\Delta C_{\mathrm{t}}$, template $(\mathrm{IgG})=2^{-[\Delta][\Delta] C \mathrm{Ct}}$. Fold enrichments were determined using the formula: $2^{-[\Delta][\Delta] \mathrm{Ct}}$ (experimental)/ $2^{-[\Delta][\Delta] C t}$ (reference, IgH). The standard error of the mean was calculated on the basis of replicate $\Delta C_{\mathrm{t}}$ values. The immunoglobulin $H$ (IgH) locus was used to normalize the fold enrichments for the individual promoters. All ChIP assays shown in the figures are representative of at least three individual experiments.

\section{ChIP-seq assay}

ChIP-seq analysis was performed as previously described [39] with antibodies against myogenin (F5D; Developmental Studies Hybridoma Bank, Iowa City, IA USA) and Myf5 (C-20; Santa Cruz Biotechnology, Santa Cruz, CA USA).

\section{shRNA knockdown}

Cell lines depleted for HEB were constructed with shRNA constructs designed by the RNAi Consortium in the pLOK.1 plasmid (Open Biosystems, Huntsville, AL USA). Five constructs targeting murine HEB and one scrambled control were linearized, transfected into $\mathrm{C}_{2} \mathrm{C}_{12}$ cells and selected with $2 \mu \mathrm{g} / \mathrm{ml}$ puromyosin. Pooled clones were selected and propagated. Depletion was confirmed at the RNA and protein levels. For the HEB depletions, the expression of E12/E47 was also confirmed at the RNA and protein levels.

\section{Additional material}

Additional file 1: Davie Supplemental figures and Table SM.

Supplemental Figures S1 through S6, Table 1 and supplemental methods are included in this file.

\section{Acknowledgements}

We thank Meiling Zhang for assistance in establishing stable cell lines expressing shRNA constructs against HEB. This work was supported by grants from the Central Research Committee, Southern Illinois University School of Medicine, and by grant 159609 from the American Cancer Society, Illinois Division, awarded to JD.

\section{Authors' contributions}

PL and JD designed the experimental approach. PL performed the described experiments, and JD wrote the manuscript with assistance from PL. Both authors read and approved the final manuscript.

\section{Competing interests}

The authors declare that they have no competing interests.

Received: 8 October 2010 Accepted: 4 April 2011 Published: 4 April 2011

\section{References}

1. Kablar B, Rudnicki MA: Skeletal muscle development in the mouse embryo. Histol Histopathol 2000, 15:649-656.

2. Parker MH, Seale P, Rudnicki MA: Looking back to the embryo: defining transcriptional networks in adult myogenesis. Nat Rev Genet 2003, 4:497-507.

3. Kassar-Duchossoy L, Gayraud-Morel B, Gomès D, Rocancourt D, Buckingham M, Shinin V, Tajbakhsh S: Mrf4 determines skeletal muscle identity in Myf5: Myod double-mutant mice. Nature 2004, 431:466-471.

4. Hasty P, Bradley A, Morris JH, Edmondson DG, Venuti JM, Olson EN, Klein WH: Muscle deficiency and neonatal death in mice with a targeted mutation in the myogenin gene. Nature 1993, 364:501-506.

5. Nabeshima Y, Hanaoka K, Hayasaka M, Esumi E, Li S, Nonaka I, Nabeshima Y: Myogenin gene disruption results in perinatal lethality because of severe muscle defect. Nature 1993, 364:532-535.

6. Blais A, Tsikitis M, Acosta-Alvear D, Sharan R, Kluger Y, Dynlacht BD: An initial blueprint for myogenic differentiation. Genes Dev 2005, 19:553-569.

7. Cao Y, Kumar RM, Penn BH, Berkes CA, Kooperberg C, Boyer LA, Young RA, Tapscott SJ: Global and gene-specific analyses show distinct roles for Myod and Myog at a common set of promoters. EMBO J 2006, 25:502-511.

8. Valdez MR, Richardson JA, Klein WH, Olson EN: Failure of Myf5 to support myogenic differentiation without myogenin, MyoD, and MRF4. Dev Biol 2000, 219:287-298.

9. Gayraud-Morel B, Chretien F, Flamant P, Gomès D, Zammit PS, Tajbakhsh S: A role for the myogenic determination gene Myf5 in adult regenerative myogenesis. Dev Biol 2007, 312:13-28.

10. Massari ME, Murre C: Helix-loop-helix proteins: regulators of transcription in eucaryotic organisms. Mol Cell Biol 2000, 20:429-440.

11. Blackwell TK, Weintraub H: Differences and similarities in DNA-binding preferences of MyoD and E2A protein complexes revealed by binding site selection. Science 1990, 250:1104-1110.

12. Sun $\mathrm{XH}$, Baltimore $\mathrm{D}$ : An inhibitory domain of $\mathrm{E} 12$ transcription factor prevents DNA binding in E12 homodimers but not in E12 heterodimers. Cell 1991, 64:459-470.

13. Braun T, Arnold $\mathrm{HH}$ : The four human muscle regulatory helix-loop-helix proteins Myf3-Myf6 exhibit similar hetero-dimerization and DNA binding properties. Nucleic Acids Res 1991, 19:5645-5651.

14. Lassar AB, Davis RL, Wright WE, Kadesch T, Murre C, Voronova A, Baltimore D, Weintraub H: Functional activity of myogenic HLH proteins requires hetero-oligomerization with E12/E47-like proteins in vivo. Cell 1991, 66:305-315.

15. Parker MH, Perry RL, Fauteux MC, Berkes CA, Rudnicki MA: MyoD synergizes with the E-protein $\mathrm{HEB} \beta$ to induce myogenic differentiation. Mol Cell Biol 2006, 26:5771-5783.

16. Cao Y, Yao Z, Sarkar D, Lawrence M, Sanchez GJ, Parker MH, MacQuarrie KL, Davison J, Morgan MT, Ruzzo WL, Gentleman RC, Tapscott SJ: Genomewide MyoD binding in skeletal muscle cells: a potential for broad cellular reprogramming. Dev Cell 2010, 18:662-674.

17. Dias P, Parham DM, Shapiro DN, Tapscott SJ, Houghton PJ: Monoclonal antibodies to the myogenic regulatory protein MyoD1: epitope mapping and diagnostic utility. Cancer Res 1992, 52:6431-6439. 
18. Wright WE, Binder M, Funk W: Cyclic amplification and selection of targets (CASTing) for the myogenin consensus binding site. Mol Cell Biol 1991, 11:4104-4110.

19. Sternberg EA, Spizz G, Perry WM, Vizard D, Weil T, Olson EN: Identification of upstream and intragenic regulatory elements that confer cell-typerestricted and differentiation-specific expression on the muscle creatine kinase gene. Mol Cell Biol 1988, 8:2896-2909.

20. Jaynes JB, Chamberlain JS, Buskin JN, Johnson JE, Hauschka SD: Transcriptional regulation of the muscle creatine kinase gene and regulated expression in transfected mouse myoblasts. Mol Cell Biol 1986, 6:2855-2864.

21. Horlick RA, Benfield PA: The upstream muscle-specific enhancer of the rat muscle creatine kinase gene is composed of multiple elements. Mol Cell Biol 1989, 9:2396-2413.

22. Donoviel DB, Shield MA, Buskin JN, Haugen HS, Clegg CH, Hauschka SD: Analysis of muscle creatine kinase gene regulatory elements in skeletal and cardiac muscles of transgenic mice. Mol Cell Biol 1996, 16:1649-1658.

23. Li H, Capetanaki Y: Regulation of the mouse desmin gene: transactivated by MyoD, myogenin, MRF4 and Myf5. Nucleic Acids Res 1993, 21:335-343.

24. Li H, Capetanaki Y: An E box in the desmin promoter cooperates with the E box and MEF-2 sites of a distal enhancer to direct muscle-specific transcription. EMBO J 1994, 13:3580-3589.

25. Ohkawa Y, Marfella CG, Imbalzano AN: Skeletal muscle specification by myogenin and Mef2D via the SWI/SNF ATPase Brg1. EMBO J 2006, 25:490-501.

26. Davie JK, Cho JH, Meadows E, Flynn JM, Knapp JR, Klein WH: Target gene selectivity of the myogenic basic helix-loop-helix transcription factor myogenin in embryonic muscle. Dev Biol 2007, 311:650-664.

27. Zhang S, Londhe $\mathrm{P}$, Zhang $\mathrm{M}$, Davie JK: Transcriptional analysis of the titin cap gene. Mol Genet Genomics 2011, 285:261-272.

28. Ott MO, Bober E, Lyons G, Arnold H, Buckingham M: Early expression of the myogenic regulatory gene, myf-5, in precursor cells of skeletal muscle in the mouse embryo. Development 1991, 111:1097-1107.

29. Tapscott SJ: The circuitry of a master switch: Myod and the regulation of skeletal muscle gene transcription. Development 2005, 132:2685-2695.

30. Gerber AN, Klesert TR, Bergstrom DA, Tapscott SJ: Two domains of MyoD mediate transcriptional activation of genes in repressive chromatin: a mechanism for lineage determination in myogenesis. Genes Dev 1997, 11:436-450.

31. Deato MD, Tjian R: Switching of the core transcription machinery during myogenesis. Genes Dev 2007, 21:2137-2149.

32. Lindon C, Montarras D, Pinset C: Cell cycle-regulated expression of the muscle determination factor Myf5 in proliferating myoblasts. J Cell Biol 1998, 140:111-118.

33. Meadows $\mathrm{E}$, Cho JH, Flynn JM, Klein WH: Myogenin regulates a distinct genetic program in adult muscle stem cells. Dev Biol 2008, 322:406-414.

34. Deato MD, Marr MT, Sottero T, Inouye C, Hu P, Tjian R: MyoD targets TAF3/ TRF3 to activate myogenin transcription. Mol Cell 2008, 32:96-105.

35. Wendt $\mathrm{H}$, Thomas RM, Ellenberger T: DNA-mediated folding and assembly of MyoD-E47 heterodimers. J Biol Chem 1998, 273:5735-5743.

36. Maleki SJ, Royer CA, Hurlburt BK: Analysis of the DNA-binding properties of MyoD, myogenin, and E12 by fluorescence anisotropy. Biochemistry 2002, 41:10888-10894.

37. de la Serna IL, Carlson KA, Imbalzano AN: Mammalian SWI/SNF complexes promote MyoD-mediated muscle differentiation. Nat Genet 2001, 27:187-190.

38. Weinmann AS, Farnham PJ: Identification of unknown target genes of human transcription factors using chromatin immunoprecipitation. Methods 2002, 26:37-47.

39. Métivier R, Penot G, Hübner MR, Reid G, Brand H, Kos M, Gannon F: Estrogen receptor-a directs ordered, cyclical, and combinatorial recruitment of cofactors on a natural target promoter. Cell 2003, 115:751-763.

doi:10.1186/2044-5040-1-14

Cite this article as: Londhe and Davie: Sequential association of myogenic regulatory factors and $\mathrm{E}$ proteins at muscle-specific genes. Skeletal Muscle 2011 1:14.

\section{Submit your next manuscript to BioMed Central and take full advantage of:}

- Convenient online submission

- Thorough peer review

- No space constraints or color figure charges

- Immediate publication on acceptance

- Inclusion in PubMed, CAS, Scopus and Google Scholar

- Research which is freely available for redistribution 